\title{
The Role of Analysts in Intra-industry Information Transfer
}

Rui Shen

acshen@ust.hk

Department of Accounting

Hong Kong University of Science and Technology

Clear Water Bay, Kowloon

Hong Kong

This draft: December, 2008

\footnotetext{
I am indebted to my supervisor, Gilles Hilary, for continuous guidance in the development of this paper. I thank the other members of my dissertation committee-Kevin Chen, Sudipto Dasgupta and Clive Lennox-as well as Kirill Novoselov for their comments and suggestions. I also thank workshop participants at Hong Kong University of Science and Technology.
} 


\title{
The Role of Analysts in Intra-industry Information Transfer
}

\begin{abstract}
I investigate the role of analysts in improving the efficiency of intra-industry information transfer. The prior literature suggests that management forecasts convey information relevant to other firms in the same industry but that this information is not immediately and efficiently impounded into their prices. The empirical evidence presented in this study shows that analysts who cover several firms in the industry help transferring this information. Specifically, I find that analysts who cover a firm issuing a management forecast provide more accurate and more timely earnings forecast revisions following the issuance of this management forecasts for the other firms in the same industry than analysts who do not cover the firm issuing the management forecast. This effect is stronger for analysts who are experienced in covering the firm issuing the management forecast. Investors are more responsive to the forecast revisions made by analysts following the firm issuing management forecast.
\end{abstract}




\section{Introduction}

Information of one firm could be extremely important for other firms in the same industry. For example, on September 15, 2008, when Lehman Brother announced its bankruptcy, the share price of Morgan Stanley dropped 13.54\%; the share price of Goldman Sachs dropped 12.13\%; and the share price of Citigroup dropped 15.14\%. Consistent with this idea, Gleason, Jenkins and Johnson (2008) show that when a firm announces earnings restatement in the industry, the three day abnormal return of other firms in this industry is $-0.5 \%$ on average. The prior literature has also shown that market participants, such as investors, analysts and managers, incorporate information originating from firms in the same industry in their valuation (Foster, 1981, Baginski, 1987), their earnings forecasts (Ramnath, 2002) and their corporate investment decisions (Durnev and Mangen, 2008).

However, the prior literature suggests that the price reaction to the news released by other firms is inefficient, even if the exact form of the inefficiency is still debated. For example, previous studies have shown that investors react strongly to other firms' news contained in earnings announcement (Foster, 1981, Han, Wild and Ramesh, 1989, Han and Wild, 1990, Freeman and Tse, 1992). Yet, two studies suggest that markets are not unbiased in processing this information. Ramnath (2002) reports that neither analysts nor investors fully incorporate the news contained in earnings surprise of the first earnings announcer in the industry in their reaction to the other firms in the same industry and exhibit under-reaction to the news. Using a different industry classification, Thomas and Zhang (2008) claim that investors over-react to 
the news contained in earnings surprises of other firms in the same industry.

This study explores channels that improve the efficiency of information transfer and focuses on management forecasts. I consider the following setting. Suppose that two firms, A and B are in the same industry and they are covered by two analysts, $\mathrm{X}$ and $\mathrm{Y}$. Analyst $\mathrm{X}$ covers both firm A and B while analyst $\mathrm{Y}$ only covers firm B (I refer to analyst $\mathrm{X}$ as MF analyst, and to analyst $\mathrm{Y}$ as non-MF analyst). Firm A issues a management forecast ( $\mathrm{I}$ refer to this firm A as MF firm). Because of the information spillover effect, both analyst $\mathrm{X}$ (i.e., the MF analyst) and analyst $\mathrm{Y}$ will revise their forecasts of firm B (I refer to this firm B as non-MF firm) at this time. Only analyst $\mathrm{X}$ has experience in forecasting MF firm A's earnings. The question is then whether this MF-experience helps analyst $\mathrm{X}$ to form more accurate earnings forecasts of firm B (non-MF firm) or not, and to the extent that it does, whether investors are more responsive to analyst X's forecast revision than to analyst Y's. If the answer to these questions is "Yes" in both cases, analysts play an important role in the efficiency of the information transfer among firms in the same industry.

In contrast to the prior literature, this study investigates the information spillover effect by using management forecasts instead of earnings announcements. Hirst, Koonce, and Venkataraman (2008) stress the importance of these forecasts and note that "they represent one of the key voluntary disclosure mechanisms by which managers establish or alter market earnings expectations, preempt litigation concerns, and influence their reputation for transparent and accurate reporting". It is perhaps then unsurprising that these forecasts also convey important information for other 
firms. For example, Baginski, (1987) has shown that investors in other firms of the same industry react strongly the news contained in these management forecasts. Management forecasts offer three advantages over earnings announcements to empirically investigate information transfer between firms. First, earnings announcements of firms in the same industry are usually clustered around the same day. This clustering makes it difficult to distinguish between the effects of different announcements. In contrast, firms, even those in the same industry, typically issue management forecasts on different dates. This creates a more powerful empirical setting to distinguish between the effect of analysts' MF-experience and other potential confounding factors. Second, earnings announcements are mandatory and audited. Although earnings are not free of biases, management forecasts are likely to be even more biased (Hirst, Koonce and Venkataraman, 2008). This creates a greater difficulty for the analysts to process the information in the forecasts and should increase the relevance of the experience in covering other firms in the same industry. Analysts with more MF-experience should have greater advantage when interpreting management forecasts than analysts with less MF-experience. Finally, management forecasts have different levels of precision. For example, the literature (Baginski and Hassell, 1997) indicates that the information contained in point management forecasts is more precise than that contained in range management forecasts. The setting of management forecasts allows the examination of the impact of the precision of the information on the efficiency of intra-industry information transfer. 
I expect that financial analysts should improve the efficiency of the intra-industry information transfer. Analysts are regarded as sophisticated participants in financial market who are experts in processing information (Beaver, 1998, Ramnath, Rock and Shane, 2008) and who are key informational intermediaries (Beaver, 1998). Thus they are capable of contributing to the intra-industry information transfer process. Given the importance of forecasts accuracy for their evaluation and promotion (Hong, Kubik and Solomon, 2000), analysts have strong incentives to incorporate all important relevant information (such as the information contained in other firms earnings forecasts) to improve their forecasts accuracy.

I also expect that MF analysts are more apt at transferring information between firms than non-MF analysts are. By learning additional information about MF firms, MF analysts improve earnings forecasts accuracy for both MF firms and non-MF firms. In contrast, non-MF analysts mainly improve their forecasts accuracy for non-MF firms by learning additional information regarding MF firms. Thus, MF analysts have stronger incentives to put more effort to understand MF firms than non-MF analysts do. As a result, MF analysts should have better knowledge of the information from MF firms than non-MF analysts do. The advantage of covering MF-firms should also be increasing with experience as analysts' ability to extract information from management forecasts should gradually increase over time. MF analysts follow both MF firms and non-MF firms and they can learn the association between MF firms and non-MF firms from past experience. Clement, Koonce and Lopez (2007) define task-specific experience as "the analyst' $\mathrm{s}$ experience in 
forecasting around a particular kind of situation or event" and show that more task-specific experienced analysts have better performance than less experienced analysts when the specific task emerges. In my setting, the specific task is to interpret and extract the information from MF firms. By definition, analysts with more MF-experience are more experienced at this task. If analysts help transferring information contained in management forecasts to investors of non-MF firms within the same industry, results in Clement, Koonce and Lopez (2007) suggest that analysts with more MF-experiences provide higher quality forecasts. Prior literature suggests that investors are more responsive to more accurate (Clement and Tse, 2003) or timelier (Cooper, Day and Levis, 2001) forecast revisions. If MF analysts and analysts with more MF-experience can provide higher quality forecasts, investors should react more strongly to revisions made by MF analysts than to the revisions made by non-MF analysts.

My empirical results are consistent with the predictions. I find that MF analysts, and particular those with more MF-experience provide more accurate earnings forecasts of non-MF firms after the management forecasts than analysts with zero or little MF-experience. The benefit of MF-experience is greater when management forecasts are imprecise or when non-MF firms are opaque. Moreover, analysts with MF-experience also provide timelier earnings revisions than analysts with zero or little MF-experience. Finally, investors are more responsive to the forecast revisions made by MF analysts than to the revisions made by non-MF analysts. This result is particularly true when there is a large institutional ownership. These different effects 
are both economically and statistically significant.

The choice of analysts to follow MF firms may be endogenous. It is possible that the innate ability of analysts is captured by the choice of following MF firms and explains the results in this study. To mitigate this concern, I do not only report analyses of MF firm coverage, but I also analyze the effect of analysts' experience of MF firms. The analysts'MF-experience not only represents their choice of coverage, but also captures their knowledge of MF firms and MF-experience suffers less from endogeneity than coverage does. However, it remains possible that analysts with a higher innate ability can have a longer tenure than analyst with a lower ability (Jacob, Lys and Neale, 1999). To further lessen this concern, I perform the following analyses. First, I control for analysts' general experience and for firm-specific experience in forecasting non-MF firms in all the regressions. If analysts' experience captures their innate ability in forecasting, analysts' general ability and their firm-specific ability should be captured by their general experience and their firm-specific experience of non-MF firms. Second, in robustness check, I follow prior literature (Clement, Koonce and Lopez, 2007) and use analysts fixed effect to control for analysts' innate ability. Results are not affected. Finally, I use analyst forecasts accuracy of year $\mathrm{t}-1$, when there is no management forecast issued by MF firms, as dependent variable. If MF-experience captures analysts' innate ability, analysts with more MF-experience should also be more accurate in year t-1's earnings forecasts than less MF-experienced analysts. However, the empirical results do not support this conclusion. There is no significant difference in year t-1' forecasts 
accuracy between analysts with MF-experience and analysts with zero or little MF-experience.

This study makes at least two contributions. First, the prior literature provides little guidance regarding the mechanisms that facilitate the intra-industry information transfer. This study is the first to examine the role analysts play in the intra-industry information transfer process. As evidenced by the literature reviewed earlier in this introduction, the transfer of information has important economic consequences. This study provides evidence that information intermediaries, financial analysts in particular, are active and effective in transferring information within the industry. This study also shows that one important determinant—analysts' experience—could affect the efficiency of information transfer within the industry and the ability of analysts in interpreting public information.

Second, this study adds to our knowledge of the determinants of analysts' forecasting accuracy and portfolio selection. The results presented in this study suggest that the experience of other firms increase analysts' forecasting accuracy when there is information transfer within the industry. These results also offer a potential explanation to the findings in Lang and Lundholm (1996) and Graham (2005). Lang and Lundholm (1996) find that analysts are more likely to cover firms with high disclosure quality. Graham (2005) finds that firms issuing management forecasts are followed by more analysts. My results suggest the existence of benefits for analysts following firms with high disclosure quality or issuing management forecasts aside from the ease to forecast the firm that disclose the 
information. Analysts may follow firms with better and timelier disclosure to gain an advantage in generating forecasts for other firms in the same industry.

The remainder of the paper is organized as follows. Section 2 develops the hypotheses. Section 3 describes sample construction and research design. Section 4 presents the results, section 5 provides additional analysis and section 6 concludes.

\section{Hypotheses}

\subsection{Forecast accuracy and MF-experience}

Firms in the same industry share similar business environments, macroeconomic conditions, technologies, and growth opportunities. The information related to one firm is also often relevant to other firms in the same industry. Perhaps not surprisingly, prior studies have documented that information affecting the stock price of a firm often affects the price of other firms in the same industry (Foster, 1981, Baginski, 1987, Gleason, Jenkins and Johnson, 2008). Ramnath (2002) indicates that analysts also revise their earnings forecasts based on industry peer firms' earnings announcement. Durnev and Mangen (2008) show that managers revise their beliefs about the value of projects and modify their own investment decisions based on accounting restatement announcements of their industry peer firms. This literature collectively shows that the information from other firms in the same industry plays a very important role when making resource allocation decisions in both external and internal capital markets. Intra-industry information transfer process will affect the efficiency of resource allocation in the economy. 
Management forecasts contain very important information in financial market (Hirst, Koonce and Venkataraman, 2008). For example, it has been shown that management forecasts affect stock prices (Pownall, Wasley and Waymire, 1993), analysts' forecasts (Baginski and Hassell, 1990), and bid-ask spreads (Coller and Yohn, 1997) of the firms issuing management forecasts. Importantly, Baginski (1987) documents that management forecasts also affect the price of similar firms in the same industry, showing the existence and the importance of information spillover effect of management forecasts.

Given the importance of information spillover effect associated with management forecasts, analysts of non-MF firms in the same industry need to interpret the news contained in management forecasts, estimate the impact on the non-MF firms, and revise their earnings forecasts of the non-MF firm. By learning information about MF firms, MF analysts, who follow MF firms, benefit from improving earnings forecasts accuracy for both MF firms and non-MF firms; while non-MF analysts only benefit from improving earnings forecasts accuracy for non-MF firms. So MF analysts have stronger incentives to put more effort in gathering information of MF firms, developing relationship with managers of MF firms, and understanding the behavior and incentives of managers of MF firms than non-MF analysts do. As a result, MF analysts should have superior knowledge of MF firms compared to non-MF analysts. It is also possible that MF-analysts have a better understanding of the association between MF firms and non-MF firms than non-MF analysts do because MF analysts follow both MF firms and non-MF firms and learn the 
association between MF firms and non-MF firms from past experience. Thus, MF analysts should better interpret the public information contained in management forecasts than non-MF analysts do. This motivates hypothesis H1a:

H1a: Analysts following a MF firm issue more accurate earnings forecasts for the non-MF firms in the same industry after a management forecast is issued by the MF firm than analysts not following the MF firm.

Clement, Koonce and Lopez (2007) define task-specific experience as "the analyst' $\mathrm{s}$ experience in forecasting around a particular kind of situation or event". In the setting of management forecast, interpreting the information released by MF firms could be regarded as a specific task. The task-specific experience is the experience of understanding and processing the information of MF firms. Analysts with more MF-experience, by definition, have more task-specific experience in this setting. They are more experienced in interpreting the information of the MF firms and more capable in translating the news to form forecasts for other firms. As suggested by Clement, Koonce and Lopez (2007), more task-specific forecasting experience is associated with higher forecast accuracy when this specific task emerges. This motivates hypothesis H1b:

H1b: Analysts with more MF-experience issue more accurate earnings forecasts for the non-MF firms in the same industry after a management forecast is issued by 
the MF firm than the analysts with less MF-experience.

2.2 Factors affecting the importance of MF-experience

MF-experience should offer advantages to analysts in forming earnings forecasts but the advantages may be conditional. When analysts with less MF-experience have no difficulty in interpreting the information contained in management forecasts, the benefits of following other firms in the same industry should be reduced. Precise information has less uncertainty and is easier to understand than imprecise information. If the information released by the MF firm is very precise, it may be easier for analysts with less MF-experience to interpret it accurately. In this case, analysts with MF-experience may not perform better than analysts with less MF-experience. In contrast, if the information released by the MF firm is imprecise, then analysts with less MF-experience may have difficulty in interpreting the information and may be inaccurate when they forecast the earnings of non-MF firms in the same industry. In this case, the benefits of MF-experience will be increased. This motivates hypothesis $\mathrm{H} 2 \mathrm{a}$ :

H2a: Analysts' MF-experience offer greater advantage in improving the forecasting accuracy of the non-MF firms earnings when the information released by the MF firms is imprecise than when the information is precise.

Characteristics of the MF-firm may also affect the benefits of the MF-experience. 
For example, if the non-MF firm is transparent, then the analysts of the non-MF firm could issue very accurate forecasts without the information from other firms. In this case, the source outside of the non-MF firm may only account for a small portion of the information used by analysts in forming their expectations of the earnings forecasts of the non-MF firm and the benefits of MF-experience may also be reduced because earnings forecasts by all analysts are already highly accurate. In contrast, if analysts forecast earnings for an opaque non-MF firm, then the analysts need to rely more on information from sources other than the non-MF firm. In this situation, outside information is more important. More MF-experience may allow analysts to better translate the information contained in management forecasts of the MF firm into the earnings forecasts of the non-MF firm. This motivates hypothesis $\mathrm{H} 2 \mathrm{~b}$ :

H2b: Analysts' MF-experience offers greater benefits in improving the forecasting accuracy of the non-MF firms earnings when the non-MF firms are opaque than when they are transparent.

\subsection{Market reaction}

In order to investigate whether financial analysts provide incremental information and whether the MF-experience helps in the intra-industry information transfer, it is important to examine how equity market reacts to the earnings revisions by MF and non-MF analysts. Prior literature suggests investors are more responsive to more accurate (Clement and Tse, 2003) or timelier forecast revisions (Cooper, Day and 
Lewis, 2001). However, if analysts do not provide incremental information to the market, the difference of forecasts accuracy between MF and non-MF analysts contains no incremental information either. Thus, investors will not react differently to the earnings revisions made by analysts with or without MF experience. In contrast, if analysts provide incremental information, investors will be more responsive to the forecast revisions made by MF analysts than to those made by non-MF analysts. ${ }^{1}$

Thus hypothesis $\mathrm{H} 3$ is:

H3: Investors are more responsive to the earnings revisions made by MF analysts than to those made by non-MF analyst.

\section{Sample and Research Design}

\subsection{Sample}

I include all point and range management forecasts defined in Anilowski et al $(2007)^{2}$. The sample covers the period from 1996 to 2006 . All firms issuing management forecasts are treated as MF firms when they issue management forecasts. All firms that share the same 4-digit SIC code with the MF firms at the time of management forecasts are treated as non-MF firms. To be included in the sample, the observations also need to satisfy the following requirements:

\footnotetext{
${ }^{1}$ Here I assume the evidence is consistent with H1a that MF analysts are more accurate than non-MF analysts.

2 Anilowski et al (2007) define point and range forecast code in their appendix. Management forecasts with "CIC Code" as "A", "F" and "Z" are classified as point forecasts, and with "CIC Code" as "B", "G" and "H" are classified as range forecasts.
} 
1) The analysts need to be active in forecasting the non-MF firms. Following Barron, Byard and Yu (2008), I define active analysts as those who issue forecasts of the non-MF firms in 45-day period before the management forecasts made by the MF firms and who also revise their forecasts in a 30-day period after the management forecasts made by the MF firms.

2) The non-MF firms have at least one active analyst with MF-experience and at least one active analyst without MF-experience.

3) The market prices of the non-MF firms are higher than five dollars at the time of management forecast.

The requirements allow us to make comparison only across active analysts.

I obtain management forecast and actual EPS from First Call database, analyst forecasts from $\mathrm{I} / \mathrm{B} / \mathrm{E} / \mathrm{S}$, financial data from COMPUSTAT, and firms return data from CRSP. There are 54,446 firm-year-analyst observations in the main sample.

\subsection{Research design}

The main focus of this study is to examine the properties of the revised forecasts of the non-MF firms and market reaction to the revised forecasts. The basic timeline of this setting is shown in figure 1 .

Insert figure 1 here 
In order to test H1a, I use the following empirical model:

$$
A F A_{i j t}=\alpha_{j}+\alpha_{t}+\beta^{*} M F_{-} \text {Analyst }_{i j t}+\gamma^{*} \text { Control Variables }+\varepsilon_{i j t}
$$

where the subscripts $\mathrm{i}, \mathrm{j}$, and t indicate analyst, firm, and year.

AFA is the analyst forecast accuracy, defined as the absolute difference between analyst i's forecast and actual EPS of the peer firm $\mathrm{j}$ after the management forecast of the MF firm, scaled by the peer firm j's price just prior to management forecast made by the MF firm.

MF_Analyst is a dummy variable. It takes the value of 1 if the analyst follows the MF firms; it takes the value of 0 otherwise.

H1a predicts that the analysts' earnings forecasts are more accurate if the analysts are MF analysts. Thus $\beta$ in model (1) is expected to be significantly negative.

$$
\mathrm{AFA}_{\mathrm{ijt}}=\alpha_{j}+\alpha_{t}+\beta * M F_{-} \mathrm{EXP}_{i j t}+\gamma * \text { Control Variables }+\varepsilon_{i j t}
$$

Model (2) is used to test H1b.

MF_EXP is the analyst's forecasting experiences of the MF firm, defined as the number of years the analyst $\mathrm{i}$ covered the MF firm; it takes the value of 0 if the analyst does not cover the MF firm at all.

$\mathrm{H} 1 \mathrm{~b}$ predicts that the analysts' earnings forecasts are more accurate if the analysts have more MF-experience. Thus $\beta$ in model (2) is expected to be significantly negative.

I include following set of control variables in the empirical model: 
(1) Firm-year fixed effect:

$\alpha_{i}$ is firm dummy and $\alpha_{j}$ is year dummy. $\quad \alpha_{i}$ and $\alpha_{j}$ control for firm-year fixed effect. OLS model with firm-year fixed effect is econometrically the same as the mean adjusted model specification in Clement, Koonce and Lopez (2007).

(2) Analyst characteristics:

Pre-accuracy is analyst pre-announcement forecast accuracy, defined as the absolute difference between analyst i's forecast before the management forecast and actual EPS of the non-MF firm $\mathrm{j}$ scaled by the non-MF firm $\mathrm{j}$ 's price one day before management forecast. Prior studies indicate that past accuracy is highly correlated with current and future accuracy (Brown, 2001). A positive relationship is expected between pre-accuracy and AFA.

Clement (1999) finds that forecast accuracy increases with longer firm-specific experience and larger employer size and decreases with more firms or industries followed. I control for these four characteristics in model (1) and (2). Broker size is the size of the analyst i's employer, defined as the number of analysts belonging to the broker. Firm experience is the analyst i's forecasting experience of the non-MF firm $\mathrm{j}$, defined as the number of years the analyst $\mathrm{i}$ issuing forecast for the non-MF firm j. No. of firms is the number of firms the analyst $i$ followed at the time of management forecast. No. of industries is the number of 2-digit SIC industries the analyst i followed at the time of management forecast.

Time to revision is the number of days taken by the analyst $i$ to revise the 
earnings forecast of the non-MF firm $\mathrm{j}$ after management forecast. The longer time the analyst takes to revise the forecasts, the more accurate forecast the analyst would like to issue because the analyst has more time to understand the information and has more chance to incorporate some new information in the forecasts. I expect the variable time to revision is negatively correlated with AFA (positively correlated with forecast accuracy).

General experience defined as the number of years the analyst issuing forecast for any firms and pre-forecast horizon defined as the number of days between the analyst i's last forecast before the management forecast and the date of management forecast announcement are also included as control variables.

(3) Firm characteristics:

Management forecast horizon is defined as the number of days between the date of management forecast of the announcing firm and the fiscal year end date of the non-MF firm j. Higher uncertainty is associated with longer forecasting horizon, thus Management forecast horizon is expected to be positively correlated with AFA.

Bundled is a dummy variable. It takes the value of 1 if the management forecast is bundled with the MF firm's annual or quarterly earnings announcement; it takes the value of 0 otherwise.

No. of analysts following defined as the number of analysts issuing forecasts for the non-MF firm $\mathrm{j}$ before the management forecast, Size defined as the natural $\log$ of the non-MF firm j's total assets (data6) in year t-1, Profitability defined as 
the income before extraordinary items (data18) scaled by total assets of the non-MF firm $\mathrm{j}$ in year $\mathrm{t}-1$ and $\mathbf{M B}$ defined as the market to book ratio $(($ data6 + data199*data25-data60)/data6) of the peer firm $\mathrm{j}$ in year $\mathrm{t}-1$ are included to control non-MF firms' information environment, profitability and growth opportunities.

In order to test $\mathrm{H} 3$, following empirical model is employed:

$$
\begin{aligned}
{\mathrm{CAR}(-1,1)_{i j t}} & =\alpha+\beta_{1} * \operatorname{Re} \text { vision }_{i j t}+\beta_{2} * M F_{-} \text {Analyst }_{i j t} * \operatorname{Re} v i s i o n \\
& +\beta_{3} * \text { Control_Variables } * \operatorname{Re} \text { vision }+\gamma_{1} * M F_{-} \text {Analyst }_{i j t} \\
& +\gamma_{2} * \text { Control_Variables }+\varepsilon_{i j t}
\end{aligned}
$$

CAR $(\mathbf{- 1 , 1 )}$ is 3-day size adjusted abnormal return around the day analysts revising their forecasts of non-MF firms.

Revision is analyst forecast revision, defined as analyst forecast minus forecasts consensus before management forecast announcements scaled by the non-MF firm j's price just prior to management forecast.

$\mathrm{H} 3$ predicts that investors will be more responsive when the revision is made by the analyst with more MF-experience, which suggests $\beta_{2}$ to be significantly positive.

Pre-accuracy is included as control variable because investors will be more responsive to the revisions made by more accurate analysts (Clement and Tse, 2003).

Investors will regard timely revisions as more informative ones because later revisions may just repeat the information already contained in early revisions. 
Thus Time to revision is included as a control variable to control the timeliness of the revisions.

Firm experience and No. of analysts following are also controlled in model (3). If there are several analysts revising their forecasts on the same day, it is difficult to know what the abnormal return around the day represents. To avoid confusion, I only include single-day forecast in testing $\mathrm{H} 3$. A forecast for firm $\mathrm{j}$ and year $\mathrm{t}$ made by analyst $\mathrm{i}$ on day $\mathrm{T}$ is defined as a single-day forecast if there are no other forecasts for the same firm-year issued by other analysts within a 3-day interval (T-1, T+1) (Chen and Matsumoto, 2006).

\section{Empirical results}

\subsection{Descriptive statistics}

Panel A of table 1 presents the pool sample descriptive statistics. The mean (median) of absolute analyst forecast error is $0.9 \%(0.4 \%)$ of the share price and the mean (median) days for analysts to make forecast revision after management forecast are 10.5 (8) days. Analysts in my sample have a median firm specific experience of 3 years and general experience of 6 years. This is comparable to the statistics in Clement, Koonce and Lopez (2007) in which sample median of analysts' firm specific experience and general experience are 3 years and 5 years respectively. Also my main sample tends to include firms with high analyst coverage (17 analysts as sample median). 
Insert table 1 here

Panel B of table 1 shows the univariate results. MF analysts are more accurate in forecasting both before and after management forecast announcement than non-MF analysts. MF-analysts are also hired by larger broker house, have longer firm specific and general experience, follow more firms and industries, and revise their forecasts faster than non-MF analysts.

Table 2 presents the correlation among variables. Most correlations are significant at the 5\% level. As prior literature suggests, AFA and pre-accuracy are highly correlated. Except the correlation between firm experience and general experience, all correlations among independent variables are less than 0.35 . This suggests that multi-colinearity is not a serious issue in estimating coefficients.

Insert table 2 here

\subsection{Hypotheses testing}

\subsubsection{Results of testing H1a and H1b}

Panel A of table 3 gives the primary regression results of H1a and H1b. As expected, the coefficients of both MF-Analyst and MF-EXP are significantly negative with t-statistics of 2.03 and 2.78 respectively. Using the coefficients of 30-day sample, increase in one standard deviation of MF-experience reduces the mean 
forecasting error by $12.92 \%$ which is economically significant. The results based on forecast revisions within 1 week or 2 weeks are also presented and consistent with main results.

The control variable firm specific experience does not behave as predicted in prior literature. Potential reasons could be that only active analysts are included in the sample and the forecast revision happens in a rather short period (30 days on average). Other control variables are generally consistent with the findings in prior studies. The average VIF (variance inflation factor) of the empirical model is less than 3 and the maximum VIF is less than 5, confirming that multi-colinearity is not a serious issue in this setting.

\subsubsection{Results of testing $\mathrm{H} 2 \mathrm{a}$ and $\mathrm{H} 2 \mathrm{~b}$}

Insert table 3 here

The results of testing $\mathrm{H} 2 \mathrm{a}$ and $\mathrm{H} 2 \mathrm{~b}$ are presented in panel $\mathrm{B}$ of table 3 . Consistent with the prediction of $\mathrm{H} 2 \mathrm{a}$ and $\mathrm{H} 2 \mathrm{~b}, \mathrm{MF}$-experience offers more advantage in forecasting earnings of non-MF firms when the management forecast is imprecise or the non-MF firms are opaque. The difference between sub-groups is both economically and statistically significant. In untabulated results, I find similar patterns for the variable of MF_Analyst (MF firm coverage). 


\subsubsection{Timeliness of forecast revisions}

Forecasting accuracy is only one measure of the relevance of the forecasts. Investors are more responsive to revisions by forecast timeliness leaders and timely forecasts are valued by the market (Cooper, Day and Lewis, 2001). If analysts have more experience in following MF firms, because of their superior knowledge on the MF firms, it will take them less time to analyze the information and translate it into the earnings forecasts of the non-MF firms. In other words, analysts with more MF-experience could revise their earnings forecasts in a timelier manner, which could make their forecasts more relevant to the market comparing to those analysts with zero or little MF-experience.

I also provide evidence on the timeliness of forecast revisions. Because analysts can only revise after management forecast and I restrict the revision period within 30 days, the time that analysts take to revise their earnings forecasts is truncated. OLS model may not be appropriate in this situation. Tobit model deals with the situation when the dependent variable is truncated or censored which is appropriate in my setting. The following tobit model with 0 and 30 as lower bound and upper bound is used:

$$
\begin{aligned}
\text { Time to revision }_{i j t} & =\alpha_{j}+\beta^{*} M F_{-} \operatorname{EXP}\left(M F_{-} \text {Analys }\right)_{i j t} \\
& +\gamma^{*} \text { Control }{ }_{\text {Variables }}+\varepsilon_{i j t}
\end{aligned}
$$

where the subscripts i, j, and t indicate analyst, firm, and year.

Time to revision has been defined before as the number of days taken by the analyst $\mathrm{i}$ to revise the earnings forecast of the non-MF firm $\mathrm{j}$ after management forecast. Because I only include the revised forecasts within 30 days after the 
management forecast announcement, the Time to revision variable is defined within $[0,30]$ interval.

As predicted, analysts with more MF-experience revise their forecasts faster. Firm fixed effects are controlled and the results are hold for both MF_Analyst and MF_EXP variables.

\subsubsection{Market reaction}

Panel A of Table 5 provides evidence consistent with H3. Investors are more responsive to the revisions made by MF analysts than to those made by non-MF analysts. The results hold after adding control variables and the average VIF of the empirical model with control variables is less than 5 . The difference in market reaction is economically significant: investors react $30 \%$ more to the revisions by $\mathrm{MF}$ analysts than to those by Non-MF analysts. This result suggests that analysts and their experience could help investors to incorporate relevant information in the information transfer process.

I then examine the impact of institutional ownership on the difference in market reaction to the forecasts made by MF and non-MF analysts. Institutional investors are regarded as sophisticated investors (Hand, 1990, Collins, Gong and Hriber, 2003). The effect of this sophistication is ambiguous ex ante. On one hand, sophisticated investors should have better understanding of the quality of analysts' forecasts than naïve investors do. This suggests that the difference in market reaction presented in panel A of Table 5 should be larger if the institutional ownership of the non-MF firm 
is larger. On the other hand, sophisticated investors should have better ability to transfer information from MF firms to non-MF firms by themselves. It may be difficult then for analysts to provide incremental information to these investors. The results presented in panel B of Table 5 are consistent with the first conjecture: when institutional ownership is high, investors react $42 \%$ more to the forecasts made by MF analysts than to the forecasts made by non-MF forecasts and this difference in market reaction is statistically significant (with t-statistics of 2.59); when institutional ownership is low, investors react only $23 \%$ more to the forecasts made by MF analysts than to the forecasts made by non-MF forecasts and this difference in market reaction is statistically insignificant (with t-statistics of 1.41). These results suggest that the difference in market reaction presented in panel A of Table 5 mainly comes from the non-MF firms with more institutional investors. In summary, all empirical results are consistent with predictions and support all the hypotheses in section 2.

\section{Additional analysis}

\subsection{Robustness check}

Jacob, Lys and Neale (1999) argue that only analysts with high innate ability could survive at the job so that analysts' experience may capture the innate ability of analysts. Thus even though pre-accuracy is controlled in all empirical models, it is possible that the innate ability of the analysts rather than experience drives the results reported in section 4 . Two additional tests are done to address this concern.

First, analyst fixed effects are included in model (1), (2) and (4) that are used to 
test $\mathrm{H} 1 \mathrm{a}, \mathrm{H} 1 \mathrm{~b}$ and the timeliness of forecast revisions. When estimating the models, the innate ability of analysts should be absorbed by analyst fixed effect. It is also consistent with prior literature (Clement, Koonce and Lopez, 2007) using analyst fixed effects to control for analysts' innate ability. The results are reported in table 6 . The results for MF_EXP are both qualitatively and quantitatively similar to the results we have earlier in table 3 and $4 .^{3}$ By adding analyst fixed effect, we can eliminate the effect of the innate ability of individual analysts and this method is also consistent with Clement, Koonce and Lopez (2007) in controlling innate ability.

Insert table 6 here

Second, in untabulated results, I use absolute analyst forecast error in year t-1 (AFA $\left._{\mathbf{t}-1}\right)$ as dependent variable in model (1) and (2). If MF_Analyst or MF_EXP captures analysts' ability rather than analysts' knowledge of MF firms, variables MF_Analyst and MF_EXP should also matter for AFA $\mathbf{A}_{\mathbf{t}-1}$. However, when using AFA $_{\text {t-1 }}$ as dependent variable, the coefficients of MF_Analyst or MF_EXP are very close to zero and insignificant (t-values are both less than 0.5 ).

\subsection{Biases in information transfer process}

Ramnath (2002) and Thomas and Zhang (2008) provide contradictory evidence regarding the biases in the intra-industry information transfer process. Ramnath (2002) argues that investors and analysts under-react to the information contained in

\footnotetext{
${ }^{3}$ Because of high correlation among analyst dummies and variable MF_analyst, the results for MF_analyst are not stable after controlling analyst fixed effect.
} 
other firms' earnings announcements, while Thomas and Zhang (2008) suggest that investors over-react to the information contained in other firms' earnings announcements. It is worth investigating whether or not analysts fully incorporate the information contained in other firms' management forecasts and how analysts' experience affects the biases. Results in Table 7 suggest that analysts over-react to management forecast news from MF firms. Moreover, analysts with more MF-experience do not provide less biased forecasts though their forecasts are more accurate. On the contrary, they tend to over-react more though the difference is not statistically significant. It is possible that they over-emphasize on the experience advantage they have.

Insert table 7 here

\section{Conclusion}

This paper investigates whether analysts improve the efficiency of intra-industry information transfer. The empirical results show that analysts with more MF-experience issue more accurate and timely forecasts than those with zero or little MF-experience. Furthermore, investors react more to the revisions made by analysts with MF-experience than to those made by analysts without MF-experience. Collectively the evidence suggests analysts help market transfer information from one source to other firms and their experience affects the efficiency of information transfer. 


\section{References:}

Anilowski, C., M. Feng and D. Skinner, 2007, Does earnings guidance affect market returns? The nature and information content of aggregate earnings guidance. Journal of Accounting and Economics 44, 36-63.

Baginski, S., 1987, Intra-industry Information Transfers Associated with Management Forecasts of Earnings. Journal of Accounting Research 25, 196-216.

Baginski, S. and J. Hassell, 1990, The Market Interpretation of Management Earnings Forecasts as a Predictor of Subsequent Financial Analyst Forecast Revision. The Accounting Review 65, 175-190.

Barron, O., D. Byard and Y. Yu, 2008, Earnings Surprises that Motivate Analysts to Reduce Average Forecast Error. The Accounting Review, 83, 303-325.

Beaver, W., 1998, Financial reporting: An accounting revolution. NJ: Prentice Hall.

Brown, L., 2001, How important is past analyst forecast accuracy? Financial Analysts Journal, 57, 44-49.

Chen, S. and D. Matsumoto, 2006, Favorable versus Unfavorable Recommendations: The Impact on Analyst Access to Management-Provided Information. Journal of Accounting Research 44, 657-689.

Clement, M., 1999, Analyst forecast accuracy: do ability, resources, and portfolio complexity matter. Journal of Accounting and Economics 27 (July), 285 - 304.

Clement, M. and S. Tse, 2003, Do investors respond to analysts' forecast revisions as if forecast accuracy is all that matters? The Accounting Review, 78, 227-249.

Clement, M., L. Koonce and T. Lopez, 2007, The roles of task-specific forecasting experience and innate ability in understanding analyst forecasting performance. Journal of Accounting and Economics 44, 378-398.

Coller, M. and T. Yohn, 1997, Management forecasts and information asymmetry: An examination of bid-ask spreads. Journal of Accounting Research 35, 181-191.

Collins, D., G. Gong and P. Hribar, 2003, Investor Sophistication and the Mispricing of Accruals, Review of Accounting Studies 8, 251-276.

Cooper, R., T. Day, and C. Lewis, 2001, Following the leader: A study of individual 
analysts' earnings forecasts. Journal of Financial Economics 61, 383-416.

Durnev, A. and C. Mangen, 2008, Corporate investments: Learning from restatements. Journal of Accounting Research, forthcoming.

Freeman, R. and S. Tse, 1992,. An earnings prediction approach to examining inter-company information transfer. Journal of Accounting and Economics 15, $509-523$.

Foster, G., 1981, Intra-industry information transfers associated with earnings releases. Journal of Accounting and Economics 3, 201-232.

Gleason, C., N. Jenkins and W. Johnson, 2008, The contagion effects of accounting restatements. The Accounting Review 83, 83-110.

Han, J., J. Wild, and K. Ramesh, 1989, Managers' earnings forecasts and intra-industry information transfers. Journal of Accounting and Economics 11, $3-33$.

Han, J. and J. Wild, 1990, Unexpected earnings and intra-industry information transfer: further evidence. Journal of Accounting Research 28, 211-219.

Hand, J., 1990, A Test of the Extended Functional Fixation Hypothesis, The Accounting Review 65, 740-763.

Hong, H., J. Kubik, and D. Solomon, 2000, Security analysts' career concerns and herding of earnings forecasts. Rand Journal of Economics 31, 121-144.

Jacob, J., T. Lys and M. Neale, 1999, Expertise in forecasting performance of security analysts. Journal of Accounting and Economics, 28, 51-82.

Kandel, E. and N. Pearson, 1995, Differential interpretation of public signals and trade in speculative markets. Journal of Political Economy, 103, 831-872.

Lang, M. and R. Lundholm, 1996, Corporate disclosure policy and analyst behavior. The Accounting Review, 71, 467-492.

Pownall, G., C. Wasley and G. Waymire, 1993, The stock price effects of alternative types of management earnings forecasts. The Accounting Review 68, 896-912.

Ramnath, S., 2002, Investor and analyst reactions to earnings announcements of related firms: An empirical analysis. Journal of Accounting Research 40, 1351-1376. 
Thomas, J. and F. Zhang, 2008, Overreaction to intra-industry information transfers. Journal of Accounting Research, forthcoming.

Venkataraman, S., Koonce, L. and Hirst, E., 2008, Management Earnings Forecasts: A Review and Framework. Accounting Horizons, Vol. 22, No. 3. 


\section{Appendix: Variable definition}

\begin{tabular}{|c|c|}
\hline Variables & Definition \\
\hline AFA & $\begin{array}{l}\text { The absolute difference between analyst i's forecast and } \\
\text { actual EPS after the management forecast scaled by the } \\
\text { firm j's price just prior to management forecast }\end{array}$ \\
\hline MF-EXP & $\begin{array}{l}\text { The number of years the analyst i covered the MF firm; } \\
\text { it takes the value of } 0 \text { if the analyst does not cover the } \\
\text { MF firm at all }\end{array}$ \\
\hline MF-Analyst & $\begin{array}{l}\text { A dummy variable takes the value of } 1 \text { if } \mathrm{MF}_{-} \mathrm{EXP}>0 \text {; } \\
\text { it takes the value of } 0 \text { if } \mathrm{MF} \_\mathrm{EXP}=0\end{array}$ \\
\hline Pre-accuracy & $\begin{array}{l}\text { The absolute difference between analyst i's forecast and } \\
\text { actual EPS of the non-MF firm j just before the } \\
\text { management forecast scaled by the firm j's price just } \\
\text { prior to management forecast }\end{array}$ \\
\hline Broker size & The number of analysts belonging to the broker \\
\hline Firm experience & $\begin{array}{l}\text { The number of years the analyst } i \text { issuing forecast for } \\
\text { the non-MF firm } j\end{array}$ \\
\hline General experience & $\begin{array}{l}\text { The number of years the analyst } i \text { issuing forecast for } \\
\text { any firms }\end{array}$ \\
\hline No. of firms followed & $\begin{array}{l}\text { The number of firms the analyst } i \text { followed at the time } \\
\text { of management forecast }\end{array}$ \\
\hline No. of industries followed & $\begin{array}{l}\text { The number of 2-digit SIC industries the analyst } \mathrm{i} \\
\text { followed at the time of management forecast }\end{array}$ \\
\hline No. of analyst following & $\begin{array}{l}\text { The number of analysts issuing forecasts for the } \\
\text { non-MF firm } \mathrm{j} \text { before the management forecast }\end{array}$ \\
\hline Time to revision & $\begin{array}{l}\text { The number of days taken by the analyst } \mathrm{i} \text { to revise the } \\
\text { earnings forecast of the non-MF firm j after } \\
\text { management forecast }\end{array}$ \\
\hline
\end{tabular}




\begin{tabular}{|c|c|}
\hline Pre-forecast horizon & $\begin{array}{l}\text { The number of days between the analyst i's last forecast } \\
\text { before the management forecast and the date of } \\
\text { management forecast announcement }\end{array}$ \\
\hline Management forecast horizon & $\begin{array}{l}\text { the number of days between the date of management } \\
\text { forecast of the announcing firm and the fiscal year end } \\
\text { date of the firm } j\end{array}$ \\
\hline Bundled & $\begin{array}{l}\text { A dummy variable takes the value of } 1 \text { if the } \\
\text { management forecast is bundled with the MF firm's } \\
\text { annual or quarterly earnings announcement and takes } \\
\text { the value of } 0 \text { otherwise }\end{array}$ \\
\hline $\mathrm{M} / \mathrm{B}$ & $\begin{array}{l}\text { The market to book ratio } \\
((\text { data6+data199*data25-data60)/data6) of the non-MF } \\
\text { firm j in year t-1 }\end{array}$ \\
\hline Profitability & $\begin{array}{l}\text { The income before extraordinary items (data18) scaled } \\
\text { by total assets of the non-MF firm } \mathrm{j} \text { in year } \mathrm{t}-1\end{array}$ \\
\hline Size & $\begin{array}{l}\text { The natural } \log \text { of the non-MF firm j's total assets } \\
\text { (data6) in year t-1 }\end{array}$ \\
\hline Revision & $\begin{array}{l}\text { Analyst forecast minus forecasts consensus before } \\
\text { management forecast announcements scaled by the } \\
\text { non-MF firm j's price just prior to management forecast }\end{array}$ \\
\hline
\end{tabular}




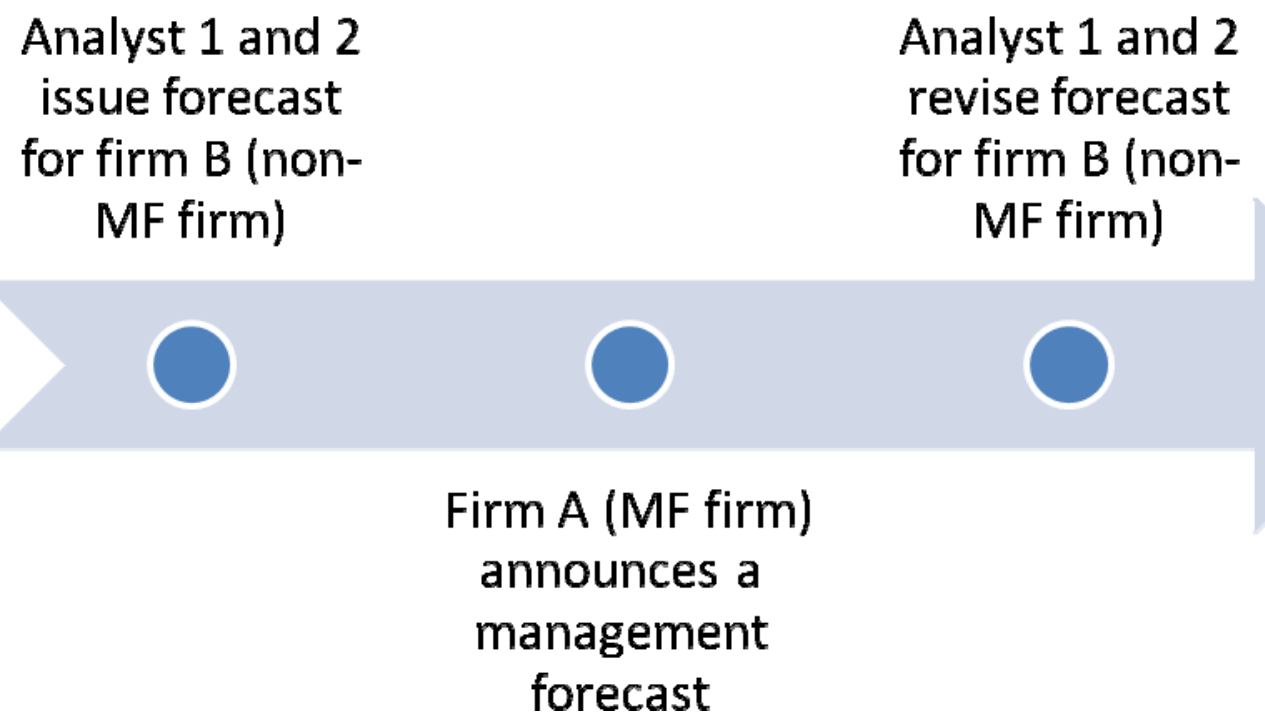

*Analyst 1 follows both firm A and B and analyst 2 only follows firm B.

Figure 1 basic timeline for this study. 
Table 1 Descriptive statistics

Panel A. Pool sample statistics

\begin{tabular}{|l|c|c|c|}
\hline \multicolumn{1}{|c|}{ Variable } & Mean & Median & Std \\
\hline AFA & 0.009 & 0.004 & 0.016 \\
\hline Pre-accuracy & 0.013 & 0.005 & 0.020 \\
\hline MF_EXP & 1.707 & 0 & 2.937 \\
\hline Broker size & 72.711 & 55 & 57.446 \\
\hline Firm experience & 4.127 & 3 & 3.286 \\
\hline General experience & 7.618 & 6 & 5.178 \\
\hline No. of firms followed & 13.848 & 13 & 5.986 \\
\hline No. of industries followed & 2.830 & 2 & 1.870 \\
\hline No. of analysts following & 17.231 & 17 & 8.221 \\
\hline Time to revision & 10.501 & 8 & 8.798 \\
\hline Pre-forecast horizon & 19.985 & 19 & 12.520 \\
\hline Management forecast horizon & 158.736 & 160 & 82.574 \\
\hline M/B & 4.139 & 3.111 & 5.423 \\
\hline Profitability & 0.049 & 0.064 & 0.123 \\
\hline Size & 8.193 & 8.079 & 1.585 \\
\hline No. of mf analysts & 3.148 & 2 & 2.967 \\
\hline No. of non-mf analysts & 5.528 & 4 & 4.600 \\
\hline
\end{tabular}


Panel B. Univariate statistics

\begin{tabular}{|l|c|c|c|c|c|c|}
\hline & & Mean & & Median & \\
\hline & Non-MF analyst & MF analyst & Difference & Non-MF analyst & MF analyst & Difference \\
\hline AFA & 0.009 & 0.009 & $0.000^{* *}$ & 0.004 & 0.003 \\
\hline Pre-accuracy & 0.013 & 0.012 & $0.001^{* * *}$ & 0.006 & 0.005 \\
\hline Broker size & 68.283 & 79.666 & $-11.383^{* * *}$ & 52 & 63 \\
\hline Firm experience & 3.908 & 4.472 & $-0.564^{* * *}$ & 3 & $-11^{* * *}$ \\
\hline General experience & 7.153 & 8.349 & $-1.196^{* * *}$ & 6 & $0^{* * *}$ & 7 \\
\hline No. of firms followed & 12.888 & 15.355 & $-2.467^{* * *}$ & 12 & $-1^{* * *}$ \\
\hline No. of industries followed & 2.792 & 2.891 & $-0.099^{* * *}$ & 2 & $-2^{* * *}$ \\
\hline Time to revision & 10.619 & 10.315 & $0.304^{* * *}$ & 8 & 2 \\
\hline
\end{tabular}

** and $^{* * *}$ indicate significant level of $5 \%$ and $1 \%$ respectively.

AFA is the absolute difference between analyst i's forecast and actual EPS after the management forecast scaled by the firm j's price just prior

to management forecast. MF-EXP is the number of years the analyst i covered the MF firm and takes the value of 0 if the analyst does not cover the MF firm at all. MF-Analyst is a dummy variable which takes the value of 1 if MF_EXP $>0$ and takes the value of 0 if MF_EXP $=$ 0 . See appendix for definitions of other variables. 
Table 2 Correlation

\begin{tabular}{|l|c|c|c|c|c|c|c|c|c|c|c|}
\hline & AFA & Pre-accuracy & MF_EXP & $\begin{array}{c}\text { Broker } \\
\text { size }\end{array}$ & $\begin{array}{c}\text { Firm } \\
\text { experience }\end{array}$ & $\begin{array}{c}\text { General } \\
\text { experience }\end{array}$ & $\begin{array}{c}\text { Time to } \\
\text { revision }\end{array}$ & $\begin{array}{c}\text { Pre-forecast } \\
\text { horizon }\end{array}$ & M/B & Profitability & Size \\
\hline AFA & & $\mathbf{0 . 7 8 9}$ & $\mathbf{- 0 . 0 1 5}$ & $\mathbf{- 0 . 0 2 9}$ & -0.000 & -0.003 & $\mathbf{0 . 0 4 9}$ & $\mathbf{0 . 0 1 7}$ & $\mathbf{- 0 . 2 7 6}$ & $\mathbf{- 0 . 2 0 8}$ & $\mathbf{- 0 . 2 2 3}$ \\
\hline Pre-accuracy & $\mathbf{0 . 8 9 4}$ & & $\mathbf{- 0 . 0 1 9}$ & $\mathbf{- 0 . 0 2 8}$ & $\mathbf{- 0 . 0 2 4}$ & $\mathbf{- 0 . 0 1 8}$ & $\mathbf{0 . 0 6 1}$ & $\mathbf{0 . 0 4 3}$ & $\mathbf{- 0 . 2 7 0}$ & $\mathbf{- 0 . 2 1 7}$ & $\mathbf{- 0 . 2 4 1}$ \\
\hline MF_EXP & $\mathbf{- 0 . 0 1 3}$ & $\mathbf{- 0 . 0 1 5}$ & & $\mathbf{0 . 1 0 9}$ & $\mathbf{0 . 1 4 0}$ & $\mathbf{0 . 1 8 0}$ & $\mathbf{- 0 . 0 2 9}$ & -0.007 & $\mathbf{- 0 . 0 3 7}$ & $\mathbf{- 0 . 0 1 6}$ & 0.003 \\
\hline Broker size & -0.007 & $\mathbf{- 0 . 0 0 8}$ & $\mathbf{0 . 0 9 1}$ & & $\mathbf{0 . 1 0 3}$ & $\mathbf{0 . 1 2 1}$ & $\mathbf{- 0 . 0 4 5}$ & $\mathbf{- 0 . 0 2 0}$ & -0.002 & $\mathbf{- 0 . 0 1 1}$ & $\mathbf{0 . 1 4 2}$ \\
\hline Firm-experience & $\mathbf{- 0 . 0 2 9}$ & $\mathbf{- 0 . 0 4 1}$ & $\mathbf{0 . 2 2 7}$ & $\mathbf{0 . 0 9 5}$ & & $\mathbf{0 . 6 4 9}$ & $\mathbf{- 0 . 0 2 3}$ & $\mathbf{- 0 . 0 2 2}$ & $\mathbf{- 0 . 0 4 6}$ & $\mathbf{0 . 1 0 4}$ & $\mathbf{0 . 1 7 7}$ \\
\hline General-experience & $\mathbf{- 0 . 0 1 3}$ & $\mathbf{- 0 . 0 2 0}$ & $\mathbf{0 . 2 6 7}$ & $\mathbf{0 . 0 7 6}$ & $\mathbf{0 . 6 5 3}$ & & -0.003 & 0.008 & $\mathbf{- 0 . 0 1 8}$ & $\mathbf{0 . 0 8 4}$ & $\mathbf{0 . 0 3 2 2}$ \\
\hline Time to revision & $\mathbf{0 . 0 6 3}$ & $\mathbf{0 . 0 6 9}$ & $\mathbf{- 0 . 0 2 8}$ & $\mathbf{- 0 . 0 3 8}$ & 0.000 & $\mathbf{0 . 0 0 9}$ & & $\mathbf{- 0 . 0 9 5}$ & $\mathbf{- 0 . 0 1 4}$ & $\mathbf{- 0 . 0 3 8 3}$ & $\mathbf{- 0 . 0 5 7}$ \\
\hline $\begin{array}{l}\text { Pre-forecast } \\
\text { horizon }\end{array}$ & $\mathbf{0 . 0 3 8}$ & $\mathbf{0 . 0 5 4}$ & -0.003 & $\mathbf{- 0 . 0 1 4}$ & $\mathbf{- 0 . 0 1 4}$ & $\mathbf{0 . 0 0 9}$ & $\mathbf{- 0 . 0 7 9}$ & & $\mathbf{- 0 . 0 1 1}$ & $\mathbf{- 0 . 0 3 9}$ & $\mathbf{- 0 . 0 7 6}$ \\
\hline M/B & $\mathbf{- 0 . 1 6 6}$ & $\mathbf{- 0 . 1 6 1}$ & $\mathbf{- 0 . 0 1 6}$ & $\mathbf{0 . 0 2 4}$ & $\mathbf{- 0 . 0 2 5}$ & $\mathbf{- 0 . 0 1 6}$ & $\mathbf{- 0 . 0 1 5}$ & $\mathbf{- 0 . 0 0 8}$ & & $\mathbf{0 . 4 4 3}$ & $\mathbf{0 . 2 8 2}$ \\
\hline Profitability & $\mathbf{- 0 . 2 0 6}$ & $\mathbf{- 0 . 2 1 6}$ & $\mathbf{0 . 0 1 6}$ & 0.002 & $\mathbf{0 . 1 1 2}$ & $\mathbf{0 . 0 9 9}$ & $\mathbf{- 0 . 0 5 7}$ & $\mathbf{- 0 . 0 4 8}$ & $\mathbf{0 . 1 7 7}$ & & $\mathbf{0 . 2 0 4}$ \\
\hline Size & $\mathbf{- 0 . 1 9 6}$ & $\mathbf{- 0 . 2 1 1}$ & $\mathbf{0 . 0 1 5}$ & $\mathbf{0 . 1 3 6}$ & $\mathbf{0 . 1 9 8}$ & $\mathbf{0 . 0 3 0}$ & $\mathbf{- 0 . 0 4 0}$ & $\mathbf{- 0 . 0 7 4}$ & $\mathbf{0 . 2 0 7}$ & $\mathbf{0 . 2 4 8}$ & \\
\hline
\end{tabular}

*Spearman correlations are presented in the up-right and Pearson correlations are presented in the down-left.

${ }^{* *}$ Correlations with $5 \%$ or higher significance are in bold characters.

AFA is the absolute difference between analyst i's forecast and actual EPS after the management forecast scaled by the firm j's price just prior to management forecast.

MF-EXP is the number of years the analyst i covered the MF firm and takes the value of 0 if the analyst does not cover the MF firm at all. See appendix for definitions of other variables. 
Table 3 Forecasting experience of MF firms and forecasting accuracy of non-MF firms

Panel A. Test of H1a and H1b

\begin{tabular}{|c|c|c|c|c|c|}
\hline & & & & $\begin{array}{c}\text { Post } \\
\text { accuracy }\end{array}$ & \\
\hline & Predicted sign & $\begin{array}{c}\text { Within } 30 \\
\text { days }\end{array}$ & $\begin{array}{c}\text { Within } 30 \\
\text { days }\end{array}$ & $\begin{array}{c}\text { Within } 2 \\
\text { weeks }\end{array}$ & $\begin{array}{c}\text { Within } 1 \\
\text { week }\end{array}$ \\
\hline \multirow[t]{2}{*}{ MF-EXP } & - & & -0.039 & -0.033 & $-0.034^{1}$ \\
\hline & & & $(-2.78)$ & $(-2.17)$ & $(-1.93)$ \\
\hline \multirow[t]{2}{*}{ MF-Analyst } & - & -0.118 & & & \\
\hline & & $(-2.03)$ & & & \\
\hline \multirow[t]{2}{*}{ Pre-accuracy } & + & 0.631 & 0.631 & 0.625 & 0.620 \\
\hline & & (103.58) & (32.38) & (26.39) & (21.84) \\
\hline \multirow[t]{2}{*}{ Broker size } & - & -0.001 & -0.001 & -0.001 & -0.002 \\
\hline & & $(-1.99)$ & $(-1.72)$ & $(-1.92)$ & $(-3.10)$ \\
\hline \multirow[t]{2}{*}{ Firm experience } & - & 0.022 & 0.025 & 0.026 & 0.048 \\
\hline & & $(\mathbf{1 . 8 5})$ & $(1.62)$ & $(1.59)$ & $(2.72)$ \\
\hline \multirow{2}{*}{$\begin{array}{l}\text { General } \\
\text { experience }\end{array}$} & - & -0.003 & 0.000 & 0.000 & -0.005 \\
\hline & & $(-0.41)$ & $(0.04)$ & $(0.01)$ & $(-0.35)$ \\
\hline \multirow{2}{*}{$\begin{array}{l}\text { No. of firms } \\
\text { followed }\end{array}$} & $?$ & -0.001 & 0.000 & 0.001 & 0.003 \\
\hline & & $(-0.12)$ & $(0.05)$ & $(0.10)$ & $(0.27)$ \\
\hline \multirow{2}{*}{$\begin{array}{l}\text { No. of industries } \\
\text { followed }\end{array}$} & $?$ & -0.016 & -0.018 & -0.026 & -0.090 \\
\hline & & $(-0.73)$ & $(-0.63)$ & $(-0.82)$ & $(-2.41)$ \\
\hline \multirow{2}{*}{$\begin{array}{l}\text { Pre-analyst } \\
\text { following }\end{array}$} & $?$ & 0.057 & 0.057 & 0.051 & 0.061 \\
\hline & & $(5.12)$ & $(1.55)$ & $(1.26)$ & $(1.28)$ \\
\hline \multirow{2}{*}{$\begin{array}{l}\text { Length of time to } \\
\text { revision }\end{array}$} & - & -0.016 & -0.016 & -0.015 & 0.021 \\
\hline & & $(-4.52)$ & $(-2.15)$ & $(-1.23)$ & $(0.72)$ \\
\hline \multirow{2}{*}{$\begin{array}{l}\text { Pre-forecast } \\
\text { horizon }\end{array}$} & ? & -0.009 & -0.009 & -0.007 & -0.017 \\
\hline & & $(-3.35)$ & $(-1.39)$ & $(-1.05)$ & $(-2.00)$ \\
\hline \multirow{2}{*}{$\begin{array}{l}\text { Management } \\
\text { forecast horizon }\end{array}$} & + & 0.014 & 0.014 & 0.014 & 0.012 \\
\hline & & (29.16) & $(9.71)$ & $(8.72)$ & $(7.38)$ \\
\hline \multirow[t]{2}{*}{ Bundled } & $?$ & 0.205 & 0.209 & 0.354 & 0.374 \\
\hline & & $(2.83)$ & $(1.31)$ & $(-1.79)$ & $(1.34)$ \\
\hline \multirow[t]{2}{*}{$\mathbf{M} / \mathbf{B}$} & $?$ & -0.011 & -0.01 & -0.021 & -0.014 \\
\hline & & $(-0.98)$ & $(-0.40)$ & $(-0.62)$ & $(-0.43)$ \\
\hline \multirow[t]{2}{*}{ Profitability } & - & -3.429 & -3.414 & -3.566 & -3.025 \\
\hline & & $(-5.24)$ & $(-2.16)$ & $(-1.94)$ & $(-1.45)$ \\
\hline \multirow[t]{2}{*}{ Size } & - & -0.001 & -0.001 & -0.001 & -0.001 \\
\hline & & $(-7.44)$ & $(-2.23)$ & $(-2.01)$ & $(-1.63)$ \\
\hline Constant & ? & 0.005 & 0.005 & 0.005 & 0.005 \\
\hline
\end{tabular}




\begin{tabular}{|l|c|c|c|c|c|}
\hline & & $(5.02)$ & $(1.48)$ & $(1.54)$ & $(1.26)$ \\
\hline Year dummy & & Yes & Yes & Yes & Yes \\
\hline Firm dummy & & Yes & Yes & Yes & Yes \\
\hline Observations & & 54446 & 54446 & 40100 & 25685 \\
\hline R-squared & & 0.84 & 0.84 & 0.84 & 0.83 \\
\hline
\end{tabular}

${ }^{1}$ all coefficients except those of pre-accuracy are multiplied by 1000 .

${ }^{2} \mathrm{t}$-statistics are clustered by firm and in parentheses.

${ }^{3}$ coefficients more than $10 \%$ significant (based on two-tail test) are in bold characters. 
Panel B Test of $\mathrm{H} 2 \mathrm{a}$ and $\mathrm{H} 2 \mathrm{~b}$

\begin{tabular}{|c|c|c|}
\hline & & MF-EXP \\
\hline \multirow{3}{*}{ Forecast form } & Range & $\begin{array}{l}-0.052 \\
(-2.84)\end{array}$ \\
\hline & Point & $\begin{array}{l}0.016 \\
(0.73)\end{array}$ \\
\hline & $\begin{array}{l}\text { Difference } \\
\text { p-value }\end{array}$ & $\begin{array}{l}-0.068 \\
(0.025)\end{array}$ \\
\hline \multirow{3}{*}{$\begin{array}{l}\text { Analyst coverage - } \\
\text { forecasting firms }\end{array}$} & High & $\begin{array}{l}-0.004 \\
(-0.29) \\
\end{array}$ \\
\hline & Low & $\begin{array}{l}-0.069 \\
(-2.78) \\
\end{array}$ \\
\hline & $\begin{array}{c}\text { Difference } \\
\text { p-value }\end{array}$ & $\begin{array}{c}0.065 \\
(0.020)\end{array}$ \\
\hline
\end{tabular}

${ }^{1}$ all coefficients except those of pre-accuracy are multiplied by 1000 .

${ }^{2}$ t-statistics are clustered by firm and in parentheses.

${ }^{3}$ coefficients more than $10 \%$ significant (based on two-tail test) are in bold characters.

AFA is the absolute difference between analyst i's forecast and actual EPS after the management forecast scaled by the firm j's price just prior to management forecast. MF-EXP is the number of years the analyst $i$ covered the MF firm and takes the value of 0 if the analyst does not cover the MF firm at all. MF-Analyst is a dummy variable which takes the value of 1 if MF_EXP $>0$ and takes the value of 0 if MF_EXP $=0 . \quad$ See appendix for definitions of other variables. 
Table 4 Forecasting experience of MF firms and other properties of forecasts of non-MF firms

\begin{tabular}{|c|c|c|c|}
\hline & Predicted sign & Time to revision & Time to revision \\
\hline \multirow[t]{2}{*}{ MF-EXP } & - & -0.065 & \\
\hline & & $(-4.70)$ & \\
\hline \multirow[t]{2}{*}{ MF-Analyst } & - & & -0.378 \\
\hline & & & $(-4.52)$ \\
\hline \multirow[t]{2}{*}{ Pre-accuracy } & $?$ & 0.937 & 1.457 \\
\hline & & $(0.35)$ & $(0.54)$ \\
\hline \multirow[t]{2}{*}{ Pre-forecast horizon } & - & -0.120 & -0.120 \\
\hline & & $(-37.47)$ & $(-37.17)$ \\
\hline \multirow[t]{2}{*}{ Broker size } & $?$ & -0.006 & -0.005 \\
\hline & & $(-7.91)$ & $(-7.84)$ \\
\hline \multirow[t]{2}{*}{ Firm experience } & $?$ & 0.078 & 0.074 \\
\hline & & $(4.52)$ & $(4.29)$ \\
\hline \multirow[t]{2}{*}{ General experience } & $?$ & -0.002 & -0.008 \\
\hline & & $(-0.23)$ & $(-0.74)$ \\
\hline \multirow[t]{2}{*}{ No. of firms followed } & + & 0.019 & 0.022 \\
\hline & & $(2.10)$ & (2.39) \\
\hline \multirow{2}{*}{$\begin{array}{l}\text { No. of industries } \\
\text { followed }\end{array}$} & + & 0.041 & 0.040 \\
\hline & & $(1.34)$ & $(1.29)$ \\
\hline \multirow{2}{*}{ Pre-analyst following } & $?$ & 0.062 & 0.046 \\
\hline & & $(5.36)$ & (3.99) \\
\hline \multirow{2}{*}{$\begin{array}{l}\text { Management forecast } \\
\text { horizon }\end{array}$} & + & 0.012 & 0.011 \\
\hline & & (22.62) & (22.33) \\
\hline \multirow[t]{2}{*}{ Bundled } & - & -4.971 & -4.988 \\
\hline & & $(-54.04)$ & $(-54.14)$ \\
\hline \multirow[t]{2}{*}{$\mathbf{M} / \mathbf{B}$} & $?$ & 0.008 & 0.007 \\
\hline & & $(0.75)$ & $(0.64)$ \\
\hline \multirow[t]{2}{*}{ ROA } & - & 0.940 & 0.610 \\
\hline & & $(1.57)$ & $(1.01)$ \\
\hline \multirow[t]{2}{*}{ Size } & - & -0.654 & -0.592 \\
\hline & & $(-8.07)$ & $(-7.11)$ \\
\hline Firm effect & & Yes & Yes \\
\hline Observations & & 54446 & 54446 \\
\hline
\end{tabular}

${ }^{1} \mathrm{z}$-statistics are clustered by firm and in parentheses.

${ }^{2}$ coefficients more than $10 \%$ significant (based on two-tail test) are in bold characters. 
Time to revision is the number of days taken by the analyst $i$ to revise the earnings forecast of the firm $\mathrm{j}$ after management forecast. MF-EXP is the number of years the analyst $i$ covered the MF firm and takes the value of 0 if the analyst does not cover the MF firm at all. MF-Analyst is a dummy variable which takes the value of 1 if MF_EXP $>0$ and takes the value of 0 if MF_EXP $=0$. See appendix for definitions of other variables. 
Table 5 Market reaction to forecasting experience of MF firms

Panel A. Pool sample market reaction

\begin{tabular}{|c|c|c|c|c|c|}
\hline & & CAR $(-1,1)$ & $\operatorname{CAR}(-1,1)$ & $\operatorname{CAR}(-1,1)$ & $\operatorname{CAR}(-1,1)$ \\
\hline & $\begin{array}{l}\text { Predicted } \\
\text { sign }\end{array}$ & & & & \\
\hline \multirow[t]{2}{*}{ Analyst revision } & + & 0.395 & 1.025 & 0.489 & 1.141 \\
\hline & & $(4.42)$ & $(4.94)$ & (6.51) & $(5.73)$ \\
\hline \multirow[t]{2}{*}{$\begin{array}{l}\text { MF analyst * } \\
\text { revision }\end{array}$} & + & 0.360 & 0.319 & & \\
\hline & & (2.69) & $(2.46)$ & & \\
\hline \multirow[t]{2}{*}{$\begin{array}{l}\text { MF_EXP } \\
\text { revision }\end{array}$} & & & & 0.032 & 0.020 \\
\hline & & & & $(1.56)$ & $(1.13)$ \\
\hline \multirow[t]{2}{*}{$\begin{array}{l}\text { Pre accuracy * } \\
\text { revision }\end{array}$} & - & & -3.999 & & -3.864 \\
\hline & & & $(-1.83)$ & & $(-1.79)$ \\
\hline \multirow[t]{2}{*}{$\begin{array}{l}\text { Time to revision * } \\
\text { revision }\end{array}$} & - & & -0.014 & & -0.015 \\
\hline & & & $(-1.72)$ & & $(-1.89)$ \\
\hline \multirow[t]{2}{*}{$\begin{array}{l}\text { Firm experience } * \\
\text { revision }\end{array}$} & + & & 0.027 & & 0.027 \\
\hline & & & $(1.21)$ & & $(1.24)$ \\
\hline \multirow[t]{2}{*}{$\begin{array}{l}\text { Analyst following } \\
\text { * revision }\end{array}$} & - & & -0.030 & & -0.031 \\
\hline & & & $(-3.05)$ & & $(-3.07)$ \\
\hline \multirow[t]{2}{*}{ MF analyst } & $?$ & 0.000 & 0.000 & & \\
\hline & & $(0.26)$ & $(0.21)$ & & \\
\hline \multirow[t]{2}{*}{ MF_EXP } & & & & 0.000 & 0.000 \\
\hline & & & & $(0.50)$ & $(0.54)$ \\
\hline \multirow[t]{2}{*}{ Pre accuracy } & $?$ & & -0.028 & & -0.026 \\
\hline & & & $(-0.66)$ & & $(-0.61)$ \\
\hline \multirow[t]{2}{*}{ Time to revision } & $?$ & & -0.000 & & -0.000 \\
\hline & & & $(-4.68)$ & & $(-4.34)$ \\
\hline \multirow[t]{2}{*}{ Firm experience } & $?$ & & 0.000 & & 0.000 \\
\hline & & & $(0.81)$ & & $(1.03)$ \\
\hline \multirow[t]{2}{*}{ Analyst following } & $?$ & & -0.000 & & -0.000 \\
\hline & & & $(-3.22)$ & & $(-3.19)$ \\
\hline Observations & & 15370 & 15370 & 15370 & 15370 \\
\hline
\end{tabular}

${ }^{1} \mathrm{t}$-statistics are clustered by firm-year-analyst and in parentheses.

${ }^{2}$ coefficients more than $10 \%$ significant (based on two-tail test) are in bold characters. 
Panel B. The impact of institutional investors on market reaction

\begin{tabular}{|l|c|c|}
\hline & $\begin{array}{c}\text { High Institutional } \\
\text { Ownership }\end{array}$ & $\begin{array}{c}\text { Low Institutional } \\
\text { Ownership }\end{array}$ \\
\hline & CAR (-1, 1) & CAR (-1, 1) \\
\hline Analyst revision & $\mathbf{0 . 9 8 4}$ & $\mathbf{1 . 0 6 8}$ \\
\hline MF analyst * revision & $\mathbf{( 2 . 6 2 )}$ & $\mathbf{( 4 . 7 1 )}$ \\
\hline & $\mathbf{0 . 4 1 6}$ & 0.231 \\
\hline Control variables & $\mathbf{( 2 . 5 9 )}$ & $(1.41)$ \\
\hline & Yes & Yes \\
\hline Observations & & 7929 \\
\hline
\end{tabular}

${ }^{1}$ t-statistics are clustered by firm-year-analyst and in parentheses.

${ }^{2}$ coefficients more than $10 \%$ significant (based on two-tail test) are in bold characters.

Revision is defined as analyst forecast minus forecasts consensus before management forecast announcements scaled by the non-MF firm j's price just prior to management forecast. MF-Analyst is a dummy variable which takes the value of 1 if MF_EXP > 0 and takes the value of 0 if MF_EXP $=0 . \quad$ See appendix for definitions of other variables. 
Table 6 Controlling analyst fixed effect

\begin{tabular}{|l|c|c|c|}
\hline & Predicted sign & Post accuracy & $\begin{array}{c}\text { Length of time to } \\
\text { revision }\end{array}$ \\
\hline MF-EXP & - & $\mathbf{- 0 . 0 3 2}$ & $\mathbf{- 0 . 0 8 0}$ \\
\hline Year fixed effect & & $\mathbf{( - 2 . 1 8 )}$ & $\mathbf{( - 5 . 5 4 )}$ \\
\hline Firm fixed effect & & Yes & No \\
\hline Analyst fixed effect & & Yes & No \\
\hline Observations & & Yes & Yes \\
\hline
\end{tabular}

${ }^{1} \mathrm{t}$-statistics and z-statistics are clustered by firm and in parentheses.

${ }^{2}$ coefficients more than $10 \%$ significant (based on two-tail test) are in bold characters.

AFA is the absolute difference between analyst i's forecast and actual EPS after the management forecast scaled by the firm j's price just prior to management forecast. Time to revision is the number of days taken by the analyst $i$ to revise the earnings forecast of the firm $\mathrm{j}$ after management forecast. MF-EXP is the number of years the analyst $i$ covered the MF firm and takes the value of 0 if the analyst does not cover the MF firm at all. MF-Analyst is a dummy variable which takes the value of 1 if MF_EXP $>0$ and takes the value of 0 if $\mathrm{MF}$ EXP $=0$. All other control variables are controlled but not tabulated. See appendix for definitions of other variables. 
Table 7 Biases in forecasts of non-MF firms with respect the news of MF firms

\begin{tabular}{|l|c|c|c|}
\hline & Predicted sign & \multicolumn{2}{|c|}{ Post AFE } \\
\hline & & & \\
\hline MF-News & $\boldsymbol{0 . 0 0 1}$ & $\mathbf{0 . 0 0 1}$ \\
\hline $\begin{array}{l}\text { MF-Analyst } \\
\text { MF-News }\end{array}$ & $\boldsymbol{( 2 . 1 6 )}$ & $\mathbf{( 1 . 8 4 )}$ \\
\hline & & & 0.000 \\
\hline Pre-AFE & & & $(0.58)$ \\
\hline & + & $\mathbf{0 . 6 4 3}$ & $\mathbf{0 . 6 4 3}$ \\
\hline Year dummy & & $\mathbf{( 3 9 . 7 7 )}$ & $\mathbf{( 3 9 . 7 7 )}$ \\
\hline Firm dummy & & Yes & Yes \\
\hline Observations & & Yes & Yes \\
\hline R-squared & & 0.82 & 0.82 \\
\hline
\end{tabular}

${ }^{1} \mathrm{t}$-statistics are clustered by firm and in parentheses.

${ }^{2}$ coefficients more than $10 \%$ significant (based on two-tail test) are in bold characters.

AFE is the signed difference between analyst i's forecast and actual EPS after the management forecast scaled by the firm j's price just prior to management forecast. MF-News is the signed difference between management forecast and pre-forecast analyst consensus of the MF firm scaled by the MF firm's price just prior to management forecast. MF-Analyst is a dummy variable which takes the value of 1 if MF_EXP $>0$ and takes the value of 0 if MF_EXP $=0$. All other control variables are controlled but not tabulated. See appendix for definitions of other variables. 